\title{
Comparison of the therapeutic effects of lobaplatin and carboplatin on retinoblastoma in vitro and in vivo
}

\author{
ZIJUN ZHOU, HUA JIANG, JIEJUN XIA and JING ZHANG \\ Department of Interventional Radiology and Vascular Anomalies, Guangzhou Women and Children's Medical Center \\ of Guangzhou Medical University, Guangzhou, Guangdong 510627, P.R. China
}

Received September 28, 2019; Accepted May 21, 2020

DOI: $10.3892 /$ ijo.2020.5085

\begin{abstract}
Retinoblastoma (RB) is one of the most aggressive malignancies affecting infants and children. Platinum drugs are commonly used in the treatment of RB; however, their efficacy is often compromised by drug resistance and severe toxicity. The present study aimed to investigate and compare the toxicity and antitumor activity of the third-generation platinum drugs, carboplatin and lobaplatin, in vitro and in vivo. The Y79 RB cell line was treated with carboplatin or lobaplatin in vitro and then used to establish xenografts in immunodeficient nude mice in vivo; the effects of pharmacological doses of these drugs were then assessed. High concentrations of carboplatin and lobaplatin markedly inhibited Y79 RB cell proliferation in vitro. In addition, the lobaplatin group exhibited higher proportions of early-stage apoptotic cells than the carboplatin group, while no significant differences in the proportions of cells in the $\mathrm{S}$ phase were observed between the 2 groups, as shown by flow cytometry. Significant changes in the $\mathrm{E} 2 \mathrm{~F} 1 / \mathrm{Cdc} 25 \mathrm{a} / \mathrm{Cdk} 2$ pathway in the RB cells were detected by RNA-seq following carboplatin or lobaplatin intervention. RT-qPCR, immunofluorescence and immunohistochemical analyses in vivo and in vitro demonstrated that the trends of drug-induced inhibition of tumor pathological changes may have been regulated through the $\mathrm{E} 2 \mathrm{~F} 1 / \mathrm{Cdc} 25 \mathrm{a} / \mathrm{Cdk} 2$ pathway, and that lobaplatin was more effective than carboplatin in controlling tumors in vivo. On the whole, the findings of the present study demonstrate that lobaplatin is associated with lower cytotoxicity and exerts more prominent therapeutic effects than carboplatin on Y79 RB cells in vitro and in mice in vivo.
\end{abstract}

Correspondence to: Professor Jing Zhang, Department of Interventional Radiology and Vascular Anomalies, Guangzhou Women and Children's Medical Center of Guangzhou Medical University, 9 Jinsui Road, Tianhe, Guangzhou, Guangdong 510627, P.R. China

E-mail: afejr@foxmail.com

Key words: lobaplatin, carboplatin, retinoblastoma, therapeutic effects

\section{Introduction}

Retinoblastoma (RB) is a primary malignant intraocular tumor common among infants and children (1) that accounts for $4 \%$ of all pediatric malignancies (2). RB can be hereditary or non-hereditary, and the spontaneous inactivation of the retinoblastoma gene $(\mathrm{RB} 1)$ at $13 \mathrm{q} 14$ has been reported to be responsible for the pathogenesis of the disease (3). Unilateral $\mathrm{RB}$ is observed in approximately $2 / 3$ of cases, while bilateral $\mathrm{RB}$ is observed in the remaining $1 / 3$ of cases, and the tumor size and tumor number per eye can vary (4). The most common and evident sign of RB is known as amaurotic cat's eye reflex or leukocoria; this retinal pathology can be viewed through the pupil and assists with accurate and early diagnosis (4). The present study aimed to investigate and compare the toxicity and antitumor activity of the third-generation platinum drugs lobaplatin with the second-generation platinum drugs carboplatin in vitro and in vivo innovatively.

$\mathrm{RB}$ therapy is administered according to the International Classification of Retinoblastoma (ICRB) guidelines (5). Currently, available therapies include eye enucleation, external beam radiotherapy, thermotherapy, cryotherapy and systemic chemotherapy, among others. Chemotherapy is the conventional and main therapeutic option for shrinking RB tumors. One of the benefits of chemotherapy over radiation therapy is that the development of secondary cancers and various other complications associated with radiation can be avoided (6). Chemotherapy can be administered through several routes, such as the systemic, intra-arterial, intravitreal and subconjunctival routes, and the typical chemotherapeutic agents, vincristine, etoposide and carboplatin (in the VEC protocol) (7) have contributed to improving the survival rates to $\geq 95 \%$. However, chemotherapeutic drugs influence all cells in the body, not only cancer cells, inducing a series of detrimental complications such as appetite and hair loss, nausea, vomiting and sore mouth (8). Despite recent advances in local delivery strategies for chemotherapy, few agents have been incorporated into the chemotherapeutic armamentarium for RB treatment (9). Thus, the exploration of novel antitumor agents with reduced side-effects and enhanced therapeutic effects in RB patients are crucial and are urgently required.

The representative 3 rd-generation platinum drug, lobaplatin (D-19466; 1,2-diamminomethylcyclobutane-platinum(II) lactate), can cause DNA damage via GG 
and AG intrastrand crosslinking to form DNA-drug adducts and to inhibit tumor activity, which may influence the expression of certain genes in tumor cells (10). Lobaplatin has exhibited promising therapeutic effects in several clinical studies; for example, it has been found to suppress proliferation and peritoneal metastasis in a preclinical model of colorectal cancer (11), to inhibit gastric cancer cells by inducing apoptosis (12), and to arrest cells in $\mathrm{S}$ phase and trigger apoptosis in the context of human non-small cell lung cancer (13). Furthermore, lobaplatin can be used to overcome the drug resistance associated with cisplatin observed in several types of cancer as it exhibits lower toxicity compared with cisplatin (14). Thus far, lobaplatin has been approved in China for the treatment of small-cell lung and metastatic breast cancer. Similarly, it has also been considered effective for the treatment of chronic myelogenous leukemia (15). Nonetheless, the effect of lobaplatin on RB and its underlying mechanism are unknown.

Carboplatin is a second-generation platinum compound that can directly inhibit DNA repair to attenuate tumor growth (15). Carboplatin has been used in the treatment of RB since the late 1980s. Currently, 6-10 cycles of carboplatin, etoposide and vincristine are typically used for systemic RB chemotherapy (16). However, there are a number of side-effects associated with systemic chemotherapy, such as autotoxicity, bone marrow suppression, nephrotoxicity and alopecia. Similarly, acute myeloid leukemia has also been found to occur in some cases, although the affected patients were also administered high doses of etoposide (17).

The present study prospectively compared the therapeutic efficacies and toxicities of lobaplatin and carboplatin in the context of RB treatment and examined the underlying molecular mechanisms of these characteristics. Specifically, the aim of the present study was to determine the effects of lobaplatin and carboplatin on Y79 RB cell proliferation, apoptosis, cell cycle progression, and tumor growth in vivo and in vitro.

\section{Materials and methods}

Cell lines and culture. The human Y79 RB tumor cell line was obtained from ATCC (The Global Bioresource Center). The tumor cells were then cultured in RPMI-1640 medium. The culture medium was supplemented with $10 \%$ fetal bovine serum (FBS) from Gibco; Thermo Fisher Scientific, Inc., $100 \mu \mathrm{g} / \mathrm{ml}$ streptomycin and $100 \mathrm{U} / \mathrm{ml}$ penicillin. The medium was maintained at $37^{\circ} \mathrm{C}$ in $5 \% \mathrm{CO}_{2}$ and $95 \%$ humidified air to provide the appropriate conditions for cell growth.

Cell viability assay. An MTT colorimetric assay, was used to assess cell viability. Briefly, the Y79 cells were plated in 96-well plates at a density of $1 \times 10^{5}$ cells per well in $100 \mu \mathrm{l}$ of complete culture medium. The cells were incubated for $24 \mathrm{~h}$ with 4 concentrations $(20,40,60$ and $80 \mu \mathrm{g} / \mathrm{ml})$ of carboplatin and 4 concentrations $(5,10,20$ and $40 \mu \mathrm{g} / \mathrm{ml})$ of lobaplatin. Subsequently, $10 \mu \mathrm{l}$ of MTT solution ( $5 \mathrm{mg} / \mathrm{ml} \mathrm{MTT} \mathrm{in} \mathrm{PBS)}$ were added, and the cells were incubated for $2 \mathrm{~h}$ at $37^{\circ} \mathrm{C}$. A microplate reader (BioTek, SynergyHT) was used to measure the absorbance at $490 \mathrm{~nm}$; the absorbance at $690 \mathrm{~nm}$ was measured to correct for the background signal.
Annexin V-fluorescein isothiocyanate (FITC)/propidium iodide (PI) apoptosis assay. The Y79 cell line was subjected to apoptosis analysis using a FITC Annexin V Apoptosis Detection kit. Cell cycle analysis was performed according to the manufacturer's protocol (KeyGEN Biotech Co., Ltd.). Specifically, Y79 cells $\left(1 \times 10^{6} / \mathrm{ml}\right)$ in $1,000 \mu \mathrm{l}$ of complete RPMI-1640 medium were seeded in 6-well plates. The Y79 cells were incubated in a controlled environment at $37^{\circ} \mathrm{C}$ for 2 days with 4 different concentrations of carboplatin $(20,40,60$ and $80 \mu \mathrm{g} / \mathrm{ml})$ and lobaplatin $(5,10,20$ and $40 \mu \mathrm{g} / \mathrm{ml})$; control cells were incubated with no additives. Subsequently, as per the manufacturer's instructions, flow cytometry was used to assess the samples ( $1 \times 10^{4}$ cells). A Beckman Coulter FC 500 flow cytometer was then used to measure the fluorescence intensities. The percentage of early apoptotic plus late apoptotic cells was considered as the apoptotic percentage. The cell cycle distributions of the different groups were analyzed. This experiment was repeated 3 times.

RNA sequencing (RNA-seq). To analyze the transcriptomes of different Y79 RB cells in vitro following treatment with carboplatin or lobaplatin, RNA-seq was employed. Differential expression analysis was also performed using the RNA-seq gene expression data, and a negative binomial distribution-based model was used as a statistical tool to address any potential issues associated with the use of RNA-seq. The Benjamini-Hochberg method was then used to adjust the resulting P-values to control the false discovery rate. Differentially expressed genes were defined as those with P-values <0.05. BioMart (http://www.biomart.org/) was then used to translate the Ensemble gene IDs into official gene symbol IDs. Similarly, the Clue GO program in Cystoscope software (https://cytoscape.org/) was employed to assess the enrichment of the differentially expressed genes. The Benjamini-Hochberg method was again used to correct the P-values, and significant gene enrichment was indicated by a P-value $\leq 0.05$.

Reverse transcription-quantitative polymerase chain reaction (RT-PCR). TRIzol reagent (Thermo Fisher Scientific, Inc.) was used to isolate total RNA from tumors or cell pellets. A NanoDrop 2000C spectrophotometer (Thermo Fisher Scientific, Inc.) was employed to quantify the isolated RNA. Subsequently, kits from Fermentas (Thermo Fisher Scientific, Inc.) were used to reverse transcribe the total RNA into cDNA with iScript Reverse Transcription Supermix (Bio-Rad Laboratories, Inc.). The primer sequences for human genes included the following: E2F1 forward, 5'GGGACTTTGCAG GCAGCGGC3' and reverse, 3'GCCGCTGCCTGCAAAGT CCC5' (reverse); Cdc25a forward, 5'ACTGAGCCGCTATTA CCGCG3' and reverse, 3'CGCGGTAATAGCGGCTCAGT5'; and Cdk2 forward, 5'AACGCGGGAAGCAGGGGCGG3' (forward) and reverse, 3'CCGCCCCTGCTTCCCGCGTT5'. The primer sequences for mouse genes included the following: E2F1 forward, 5'CCGCCATGGGCCCGCGCCGC3' and reverse, 3'GCGGCGCGGGCCCATGGCGG5'; Cdc25a forward, 5'GGAGAAAAAAAGTGAGGCGA3' and reverse, 3'TCGCCTCACTTTTTTTCTCC5'; and Cdk2, forward, 5'TGGACAAATTGTCAAGGGCT3' and reverse, 3'AGC CCTTGACAATTTGTCCA5'. qPCR analysis was then 
performed using SYBR-Green Master Mix and a CFX96 Real-Time PCR Detection System (Bio-Rad Laboratories, Inc.) following the instructions of the manufacturer. The comparative cycle threshold $(\mathrm{Cq})(\Delta \Delta \mathrm{Cq})$ method was used to analyze the data (18). The expression data for each sample were normalized to GAPDH (forward, 5'AACTTTGGCATT GTGGAAGG3' and reverse, 3' ACACATTGGGGGTAGGA ACA5').

Immunofluorescence microscopy. Following incubation with carboplatin and lobaplatin, 1X PBS was used to prepare the cells. Subsequently, the cells were briefly fixed for $5 \mathrm{~min}$ using methanol and acetone (1:1, v:v), and 3\% BSA was used to block the cells for half a day at room temperature. The cells were then incubated for half a day at $4^{\circ} \mathrm{C}$ with anti-E2F1 (1:300; cat. no. HPA008003, Sigma-Aldrich; Merck KGaA), anti-Cdc25a (1:300; cat. no. WH0000993M1, Sigma-Aldrich; Merck KGaA) and anti-Cdk2 (1:100; cat. no. SAB5300328, Sigma-Aldrich; Merck KGaA) antibodies. After washing, the cells were incubated with an Invitrogen brand Alexa Fluor 488-conjugated secondary antibody (1:500; cat. no. 913921 Thermo Fisher Scientific, Inc.) for $1 \mathrm{~h}$ at room temperature. Subsequently, the nuclei were stained for 5 min using the blue fluorescent stain DAPI (Sigma-Aldrich; Merck KGaA). Finally, 1X PBS was used to wash the samples, which were then observed using a Carl Zeiss AG fluorescence microscope.

Animals and tumor xenograft growth assay. All animal experiments complied with the guidelines established by the Association for Research in Vision and Ophthalmology for the use of animals in ophthalmic and vision research and were approved by the Institutional Ethics Board of Guangzhou Women and Children's Medical Center. BALB/c (nu/nu) nude mice (4-5 weeks old) were procured from the Guangdong Medical Laboratory Animal Center. There were 84 nude mice used and euthanized in the present study to evaluate the tumor growth curve, pathological changes, and the mRNA and protein levels of cytokines. In the experiment, the mice were anesthetized intraperitoneally with chloral hydrate $(400 \mathrm{mg} / \mathrm{kg})$ to minimize suffering. Mice were housed under standard laboratory conditions $\left(22 \pm 2^{\circ} \mathrm{C}, 60 \%\right.$ relative humidity, 12/12 h light/dark cycle, and provided with food and water ad libitum), and animal health and behavior were daily monitored.

Xenograft tumors were established bilaterally in each mouse with a single subcutaneous injection in the right flank consisting of $1 \times 10^{7} / \mathrm{ml} \mathrm{Y79} \mathrm{RB} \mathrm{cells} \mathrm{suspended} \mathrm{in} 0.3 \mathrm{ml}$ of a 1:1 mixture of ice-cold Matrigel basement membrane matrix (BD Biosciences) and RPMI-1640 medium. Once the tumor masses became visible in the 2 nd week, the mice were randomly assigned to 4 groups and treated with different medications: Group 1 was the control group, group 2 comprised mice injected with PBS (group 2a received tail vein injections of PBS every 3 days for 1 week, and group $2 b$ received tail vein injections of PBS every 3 days for 2 weeks), group 3 consisted of mice injected with carboplatin $(20 \mathrm{mg} / \mathrm{kg}$; group 3a received tail vein injections of PBS every 3 days for 1 week, and group $3 b$ received tail vein injections of PBS every 3 days for 2 weeks) according to a previous study (19) and group 4 comprised mice injected with lobaplatin $(750 \mu \mathrm{g} / \mathrm{kg}$; group 4a received tail vein injections of PBS every 3 days for 1 week, and group $4 \mathrm{~b}$ received tail vein injections of PBS every 3 days for 2 weeks) according to a previous study (20). There were 7 subgroups of 4 groups of mice, and the mice in each subgroup were used in 4 different experiments, namely tumor growth curve analysis, hematoxylin and eosin (H\&E) staining, histological analysis and immunohistochemistry (IHC) and RT-qPCR. Each experiment contained 3 mice per subgroup, and independent experiments were performed ( $7 \times 3 \times 4=84$ mice). Two-dimensional external measurements were obtained twice each week with calipers, and the tumor volume was calculated with the equation volume $\left(\mathrm{mm}^{3}\right)=4 / 3 \times \pi \times(\mathrm{L} / 2) \times(\mathrm{W} / 2)^{2}$. The weights of the mice were also recorded once each week. The mice were euthanized by cervical dislocation following an intraperitoneal injection of chloral hydrate $(400 \mathrm{mg} / \mathrm{kg})$. After sacrificing the tumor-bearing mice, the tumors were collected. A combination of methods was used to ensure the death of the mice, including a firm toe pinch, a lack of visible respiration, a lack of digitally palpable heartbeat or respiration, grey mucous membranes and the loss of corneal reflex.

Histological analysis and IHC. Prior to paraffin-embedding, the eyes were fixed in Bouin's solution or formalin for 1 day. The paraffin blocks were sectioned at a thickness of $4 \mu \mathrm{m}$, and the sections were stained with H\&E; cat. no. C0105, Beyotime Institue of Biotechnology). The specific steps included: i) Deparaffinization of the sections: The slide was place on a burner and then in xylene; ii) hydration: Tissue sections were hydrated by passing through decreasing concentrations of alcohol baths and water (100, 90, 80 and 70\%); iii) staining in hematoxylin for 3-5 min; iv) washing under running tap water until the sections were 'blue' for $\leq 5 \mathrm{~min}$; v) differentiation in $1 \%$ acid alcohol $(1 \% \mathrm{HCl}$ in $70 \%$ alcohol) for $5 \mathrm{~min}$; vi) washing udner running tap water until the sections were again blue by dipping in an alkaline solution (e.g., ammonia water) followed by washing under tap water again; vii) staining in $1 \%$ eosin $\mathrm{Y}$ for $10 \mathrm{~min}$; viii) washing under tap water for 1-5 min ix) dehydrationg in an increasing concentration of alcohol and clearing in xylene; $x$ ) mounting in mounting media and observation under a microscope. The following antibodies were used in the immunohistochemical analysis: Anti-E2F1 (1:1,000; cat. no. ABIN969516, Biocompare), anti-Cdc25a (1:100; cat. no. ab75743, Abcam) and anti-Cdk2 (1:300; cat. no. ab6433, Abcam). The paraffin-embedded sections were first treated with xylene, a graded ethanol series and TBS Tween-20 (TBST); subsequently, antigen retrieval was performed by microwaving the sections in sodium citrate buffer (0.01 M, pH 6.0). $\mathrm{H}_{2} \mathrm{O}_{2}(3.5 \%)$ was then employed to block endogenous peroxidase, and the sections were incubated with primary antibodies overnight for immunohistochemical analysis. Biotin-conjugated secondary antibodies, goat anti-rabbit IgG H\&L (HRP) (cat. no. ab205718, Abcam), and goat anti-mouse IgG H\&L (HRP) (cat. no. ab205719, Abcam) were diluted 1:2,000 with a biotin peroxidase complex (Vectastain ABC with DAB substrate; Vector Laboratories) for $1 \mathrm{~h}$ at room temperature. The sections were then washed in PBS. Subsequently, the sections were developed for $30 \mathrm{sec}$ at room temperature with a freshly prepared 3,3'-diaminobenzidine solution and counterstained using hematoxylin at room temperature for $45 \mathrm{sec}$. The sections were rehydrated through 
A

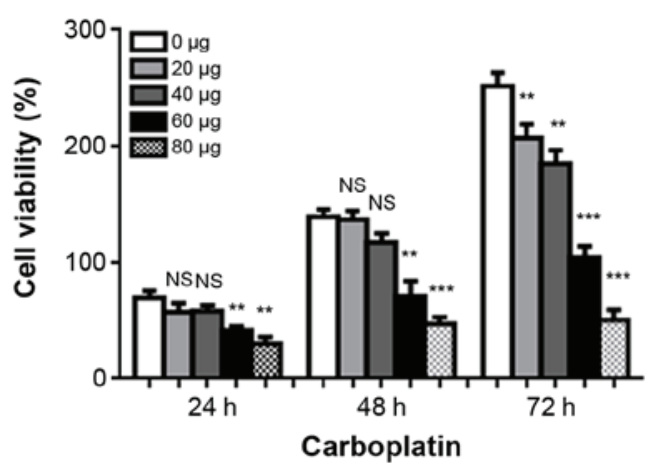

B

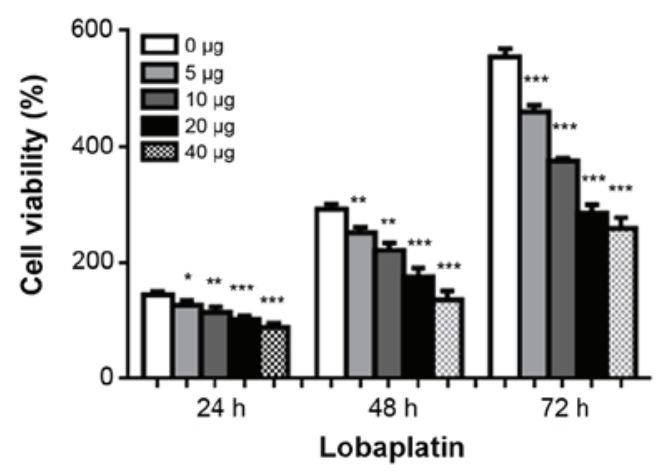

C
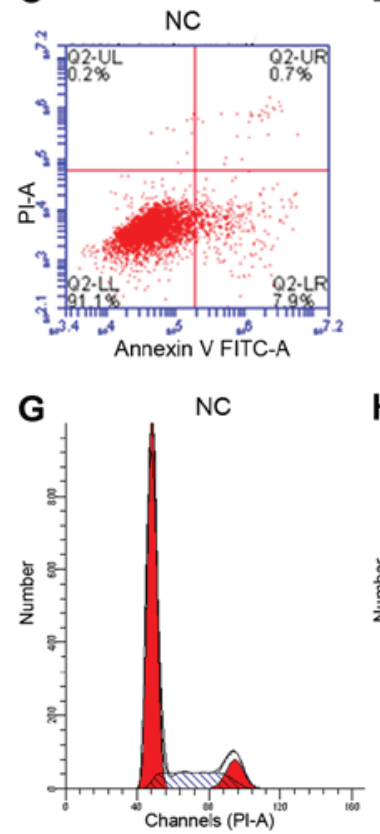

D

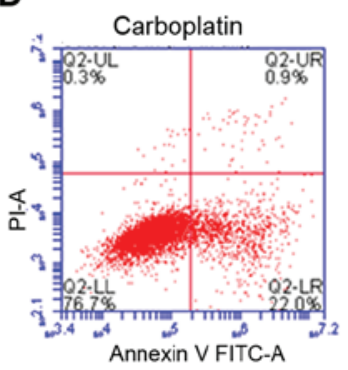

H

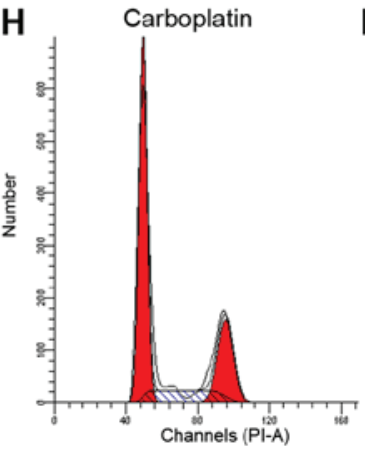

E
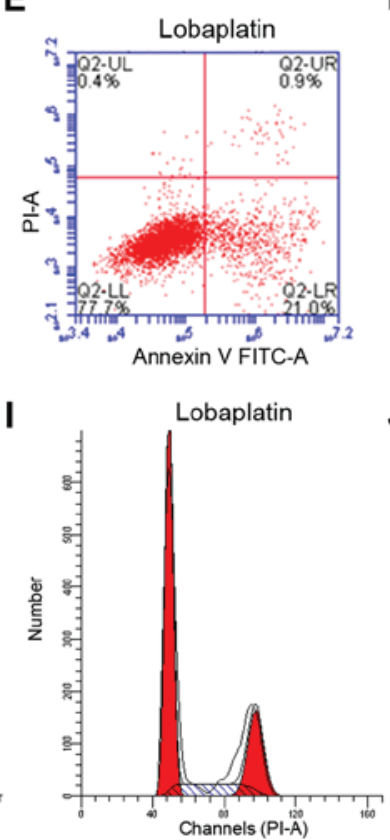

$\mathbf{F}$
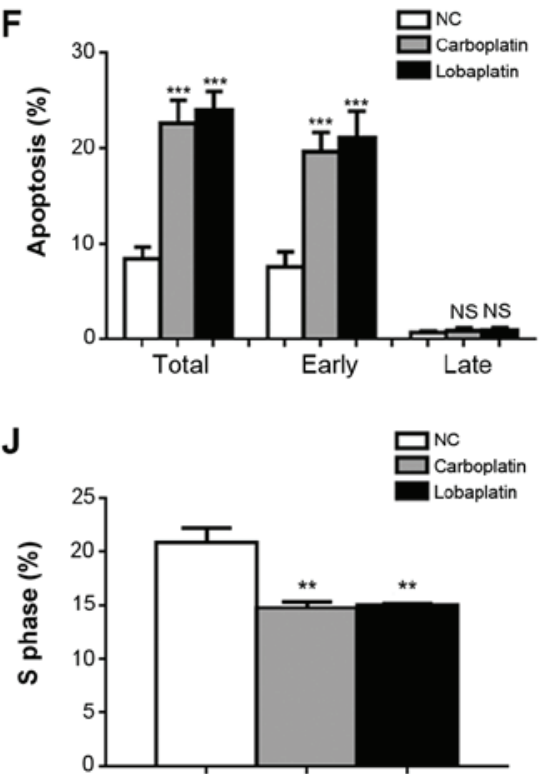

Figure 1. Carboplatin and lobaplatin induce various degrees of apoptosis and cell cycle changes in Y79 cells. Cell viability decreased gradually upon treatment with increasing concentrations of (A) carboplatin $(0,20,40,60$ and $80 \mu \mathrm{g} / \mathrm{ml})$ or (B) lobaplatin $(0,5,10,20 \mathrm{and} 40 \mu \mathrm{g} / \mathrm{ml})$ for $24,48 \mathrm{or} 72 \mathrm{~h}$. The percentages of apoptotic and early apoptotic cells in the carboplatin and lobaplatin groups differed significantly from those in the NC group. (C-F) Representative results of apoptosis in the NC, carboplatin, and lobaplatin groups. (G-J) The proportions of cells in the S phase were lower in the carboplatin and lobaplatin groups than in the NC group. NS, not significant $(\mathrm{P}>0.05) ;{ }^{*} \mathrm{P}<0.05,{ }^{* *} \mathrm{P}<0.01$ and ${ }^{* * *} \mathrm{P}<0.001$ vs. control (no treatment) or NC group.

a graded series of ethanol, washed with xylene and mounted at room temperature. A Carl Zeiss light microscope (magnification, $\mathrm{x} 20$ ) was used to estimate the expression of E2F1, Cdc25a and $\mathrm{Cdk} 2$.

Statistical analysis. The statistical analysis was performed using SPSS 23.0 (SPSS Inc.). The data from the analysis of cell viability, the apoptotic percentage and the number of cells in the $\mathrm{S}$ phase are reported as the means \pm standard error of the mean (SEM), and one-way ANOVA test followed by Bonferroni's post hoc test was used to determine the statistical significance of the differences among multiple groups. $\mathrm{P}<0.05$ was considered to indicate a statistically significant difference.

\section{Results}

Carboplatin and lobaplatin induce various degrees of apoptosis and cell cycle changes in Y79 RB cells. To explore the toxicity of carboplatin and lobaplatin toward Y79 RB cell viability, the cells were exposed to various concentrations of carboplatin $(0,20,40,60$ and $80 \mu \mathrm{g} / \mathrm{ml})$ or lobaplatin $(0,5$, 10,20 and $40 \mu \mathrm{g} / \mathrm{ml}$ ) for 2-3 days. Similarly, the inhibitory effects of carboplatin and lobaplatin on Y79 cell proliferation in vitro were determined using an MTT assay. Carboplatin and lobaplatin inhibited Y79 cell viability in a dose-dependent manner (Fig. 1A and B, respectively). Cell viability decreased gradually with the increasing concentrations of carboplatin and lobaplatin; at $72 \mathrm{~h}$, cell viabilities were $251.7 \pm 6.692$, $207.0 \pm 6.658(\mathrm{P}<0.01), 185.0 \pm 6.658(\mathrm{P}<0.01), 104.0 \pm 5.859$ $(\mathrm{P}<0.001)$ and $50.33 \pm 5.239(\mathrm{P}<0.001)$ in the $0,20,40,60$ and $80 \mu \mathrm{g} / \mathrm{ml}$ carboplatin groups, respectively (Fig. 1A) and 554.0 $\pm 8.718,460.7 \pm 6.360(\mathrm{P}<0.001), 375.3 \pm 2.603(\mathrm{P}<0.001)$, $286.3 \pm 8.172(\mathrm{P}<0.001$ and $258.7 \pm 10.91(\mathrm{P}<0.001)$ in the groups treated with $0,5,10,20$ and $40 \mu \mathrm{g} / \mathrm{ml}$ lobaplatin, respectively (Fig. 1B).

Subsequently, flow cytometry was performed to assess the effects of carboplatin and lobaplatin on Y79 cell early and late apoptosis, and $\mathrm{S}$ phase cell cycle arrest. The total apoptotic percentages were $8.467 \pm 0.696 \%, 22.67 \pm 1.419 \%(\mathrm{P}<0.001$ and $24.00 \pm 1.155 \%(\mathrm{P}<0.001)$ in the control, carboplatin 
A

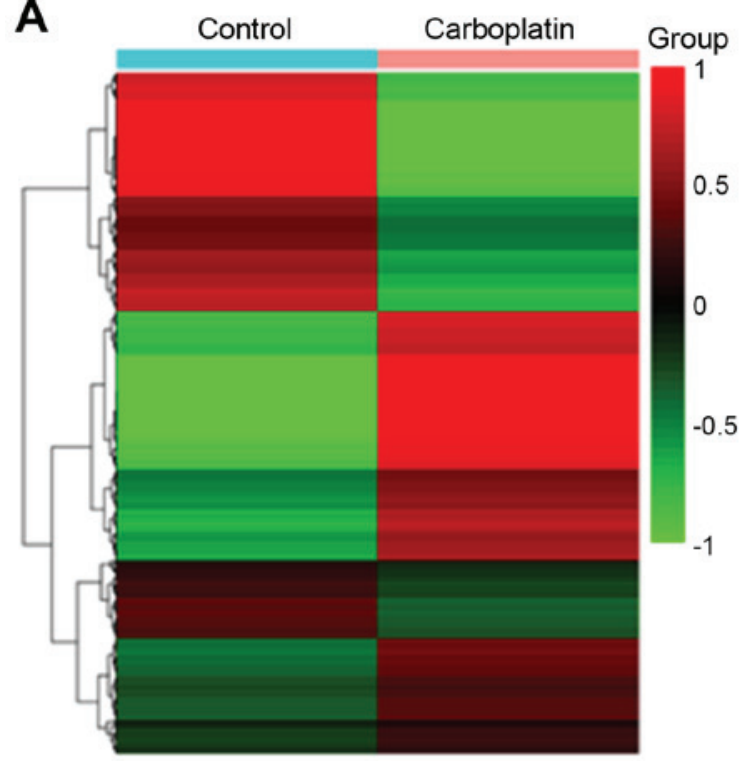

C

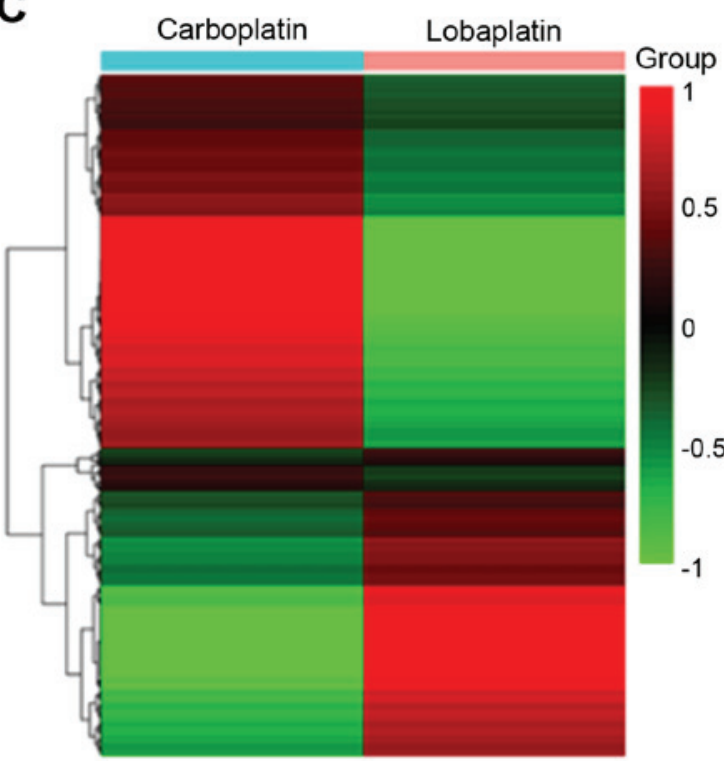

B

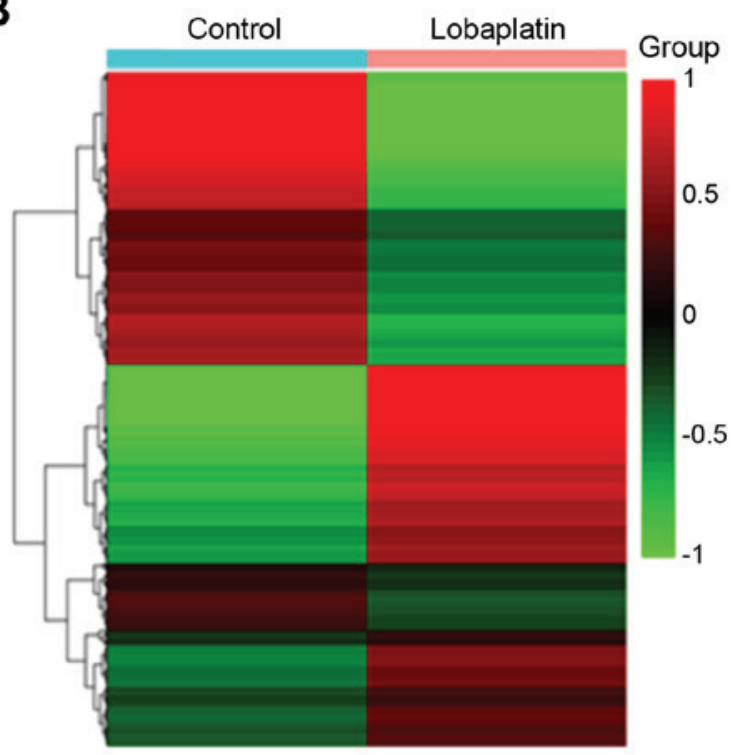

D

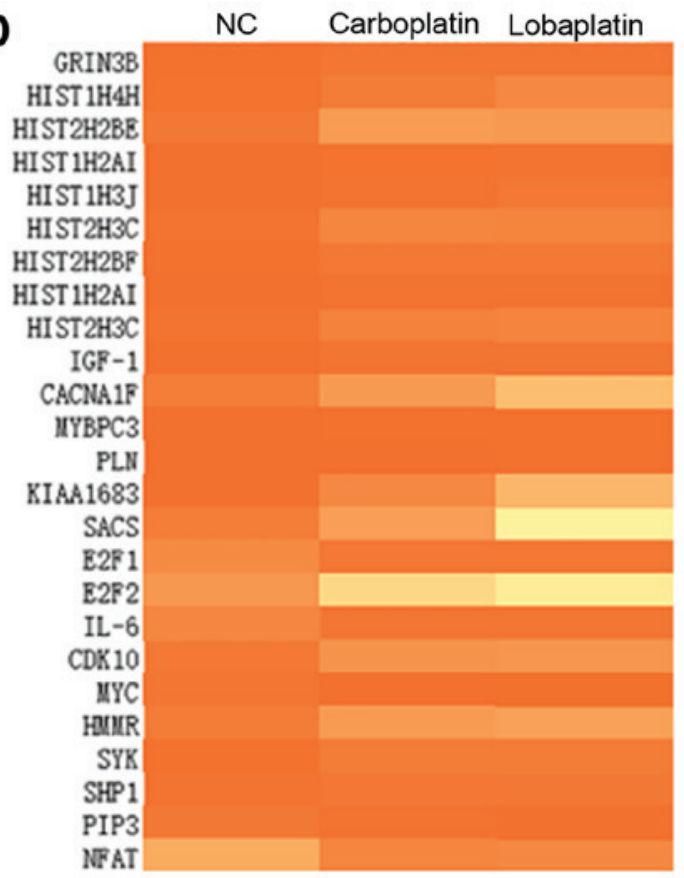

Figure 2. Gene expression changes in the carboplatin- and lobaplatin-treated groups. (A-C) Heatmaps showing the normalized expression of associated genes in the NC, carboplatin and lobaplatin groups. (D) Results of a cluster analysis of the gene expression levels [in fragments per kilobase per million (FPKM)] in each sample.

and lobaplatin groups, respectively; the early apoptotic percentages were $8.467 \pm 0.6960 \%, 21.63 \pm 1.450 \%(\mathrm{P}<0.001)$ and $22.67 \pm 1.419 \%(\mathrm{P}<0.001)$, respectively; and the late apoptotic percentages were $0.7367 \pm 0.0857 \%, 0.9200 \pm 0.1620 \%$ $(\mathrm{P}=0.814)$ and $0.9767 \pm 0.1690 \%(\mathrm{P}=0.769)$ in the control, carboplatin and lobaplatin groups, respectively (Fig. 1C-F). Additionally, the carboplatin and lobaplatin groups exhibited lower proportions of Y79 cells arrested in the S phase than the negative control (NC) group. The proportion of cells in $\mathrm{S}$ phase in the control group was $22.49 \pm 1.51 \%$, whereas the proportions in the carboplatin and lobaplatin groups were $14.62 \pm 0.60 \%(\mathrm{P}<0.01)$ and $14.99 \pm 1.20 \%(\mathrm{P}<0.01)$, respectively. However, no significant differences were observed between the carboplatin and lobaplatin groups $(\mathrm{P}=0.8546)($ Fig. $1 \mathrm{G}-\mathrm{J})$.
Gene expression changes in the carboplatin- and lobaplatin-treated groups. RNA-seq was performed to identify mRNA expression patterns in the different groups (Fig. 2A-C) to assess the effects of lobaplatin and carboplatin on Y79 cells. Cluster analysis revealed differences among the 3 groups, confirming that the RNA-seq data of the present study were suitable for differential expression analysis (Fig. 2D). In total, 2,525 genes were differentially expressed in the carboplatin group compared to the control group (Fig. S1A-a), including 1,353 upregulated genes and 1,172 downregulated genes. In addition, 5,553 genes were differentially expressed in the lobaplatin group compared to the control group (Fig. S1A-b), including 2,582 upregulated genes and 2,971 downregulated genes, while 3,724 genes were differentially expressed in the 

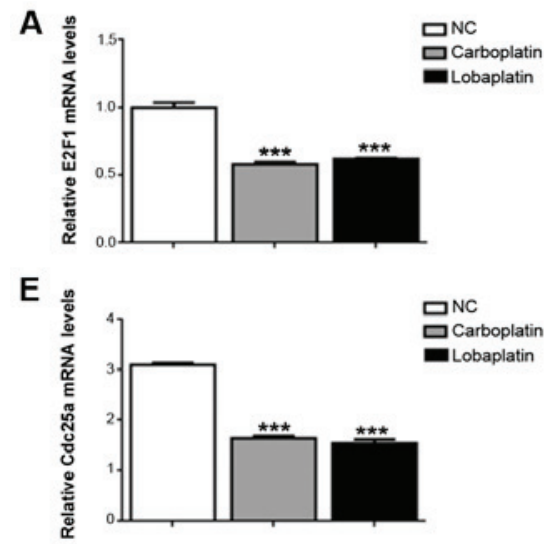

I
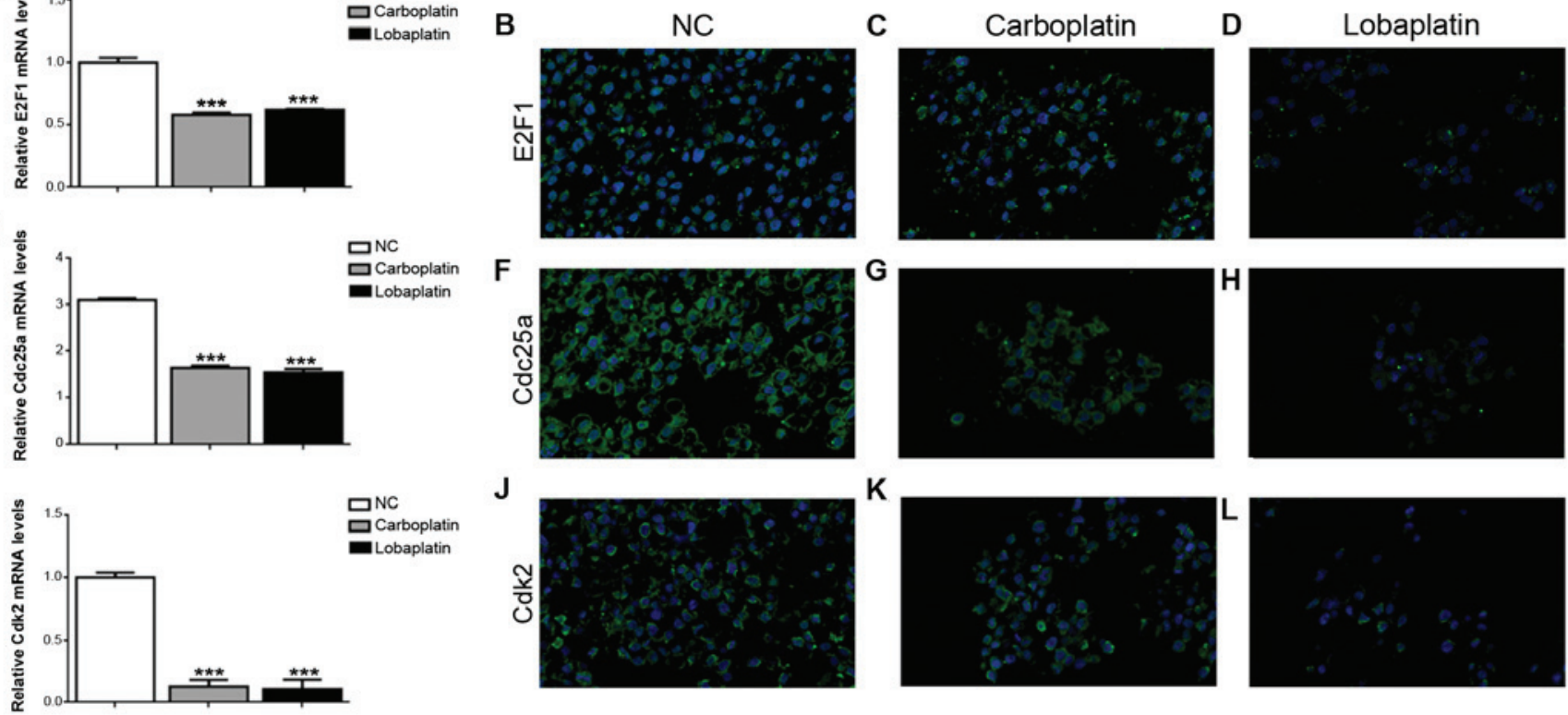

$\mathbf{J}$
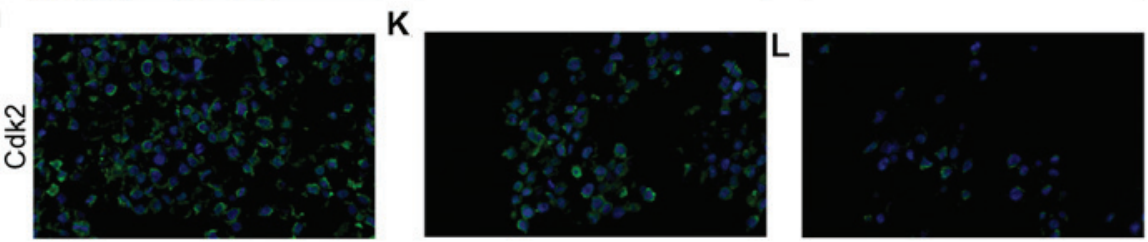

Figure 3. Expression of the transcription factors E2F1, Cdc25a and Cdk2 was increased in carboplatin-treated and lobaplatin-treated Y79 cells. Protein and mRNA levels of (A-D) E2F1 (E-H) Cdc25a and (I-L) Cdk2 in Y79 cells detected by RT-PCR analysis and immunofluorescence microscopy in the NC, carboplatin and lobaplatin groups. Magnification, $\mathrm{x} 40$. NS, not significant $(\mathrm{P}>0.05) ;{ }^{* * *} \mathrm{P}<0.001$ vs. NC group.

carboplatin group compared to the lobaplatin group, including 1,534 upregulated genes and 2,190 downregulated genes (Fig. S1A-c). The important biological functions were assessed in these 3 groups through Gene Ontology (GO) enrichment analysis (Fig. S1B-a-c), and the results revealed enrichment for 'E2F/IGF1/CACNA1F/TNNC1/TGFB3/CACNG6/ MYBPC3/CACNA2D3/ADCY1/PLN', 'E2F/IGF1/NUPR1/ HIST1H3J/HIST2H3C/HIST2H3A/HIST1H3B/HIST1H3E/ HIST1H3H/HIST1H3D' and 'E2F/MYC/CDKN2B/HIPK4/ CALML6' in the groups (Fig. 2D). Notably, E2F1 was a significant gene in all groups (Fig. 2D).

Expression of the transcription factors, E2F1, Cdc $25 a$ and $C d k 2$, is decreased in carboplatin-treated and lobaplatin-treated Y79 RB cells. E2F1 is a transcriptional regulator of genes essential for $\mathrm{RB}$, and the present study detected the decreased release of nuclear E2F1 in both the carboplatin-treated and lobaplatin-treaded Y79 cells, further verifying the results of the RNA-seq analysis. The protein and mRNA levels of E2F1 were downregulated in the Y79 cells treated with carboplatin or lobaplatin compared to the normal control Y79 cells, with mRNA expression levels of $0.53 \pm 0.02$ in the carboplatin group, lower than those of $0.56 \pm 0.01$ in the lobaplatin group $(\mathrm{P}<0.001)$ and $1.00 \pm 0.04$ in the $\mathrm{NC}$ group $(\mathrm{P}<0.001)$ (Fig. 3A). The results of immunofluorescence staining revealed similar tendencies in the E2F1 protein levels in these 3 groups (Fig. 3B-D). The Cdc25a mRNA expression levels were $3.10 \pm 0.04$ in the $\mathrm{NC}$ group, markedly higher than the levels of $1.65 \pm 0.05(\mathrm{P}<0.001)$ and $1.55 \pm 0.07(\mathrm{P}<0.001)$ in the carboplatin and lobaplatin groups, respectively (Fig. 3E), and it displayed the least negative staining in the lobaplatin group compared with the carboplatin and control groups (Fig. 3F-H). In addition, the Cdk2 mRNA expression level was $1.00 \pm 0.04$ in the NC group, markedly higher than the levels of $0.12 \pm 0.003(\mathrm{P}<0.001)$ and $0.08 \pm 0.005(\mathrm{P}<0.001)$ in the carboplatin and lobaplatin groups, respectively (Fig. 3I), in which the protein levels exhibited similar same expression trends (Fig. 3J-L).

Carboplatin and lobaplatin at pharmacological doses successfully inhibit the growth of human RB xenografts in vivo. The mean tumor sizes determined at necropsy on days $7,10,14,17,21,24$ and 28 were $0.65 \pm 0.001,5.63 \pm 0.002$, $14.98 \pm 0.003,26.47 \pm 0.001,50 \pm 0.001,115 \pm 0.002$ and $220 \pm 0003$, respectively, in the control group; $0.73 \pm 0.001$, $5.79 \pm 0.002,15.12 \pm 0.003,28.47 \pm 0.001,48.61 \pm 0.001$, $110 \pm 0.002$ and $223 \pm 0003$, respectively, in the NC 1-week (W) group; $0.70 \pm 0.001,5.74 \pm 0.002,15.19 \pm 0.003,28.17 \pm 0.001$, $48.42 \pm 0.001,118.44 \pm 0.002$ and $213.52 \pm 0003$, respectively, in the NC $2 \mathrm{~W}$ group; $0.72 \pm 0.001,5.54 \pm 0.002,15.31 \pm 0.003$, $14.23 \pm 0.001,6.21 \pm 0.001,2.91 \pm 0.002$ and $0.51 \pm 0003$, respectively, in the carboplatin $1 \mathrm{~W}$ group; $0.76 \pm 0.001$, $5.58 \pm 0.002,14.85 \pm 0.003,13.33 \pm 0.001,5.98 \pm 0.001,0 \pm 0.002$ and $0 \pm 0003$, respectively, in the carboplatin $2 \mathrm{~W}$ group; $0.76 \pm 0.001,5.57 \pm 0.002,15.48 \pm 0.003,12.08 \pm 0.001,5.01 \pm 0.001$, $1.69 \pm 0.002$ and $0.20 \pm 0003$, respectively, in the lobaplatin $1 \mathrm{~W}$ group; and $0.70 \pm 0.001,5.69 \pm 0.002,15.21 \pm 0.003,10.41 \pm 0.001$, $5.21 \pm 0.001,0 \pm 0.002$ and $0 \pm 0003$, respectively, in the lobaplatin $2 \mathrm{~W}$ group (Fig. 4B and C).

H\&E staining revealed that cell proliferation was significantly inhibited in both ocular and subcutaneous tumors. In the control group and NC group, the tumor cells broke through the basement membrane, and extradermal growth occurred. However, the injection of carboplatin or lobaplatin significantly inhibited tumor growth (Fig. 4D) and significantly decreased cell division in subcutaneous tumors (Fig. 4E).

E2F1, Cdc25a and Cdk2 expression is decreased following carboplatin or lobaplatin treatment. The mRNA and protein levels of E2F1, Cdc25a and Cdk2 were evaluated following 


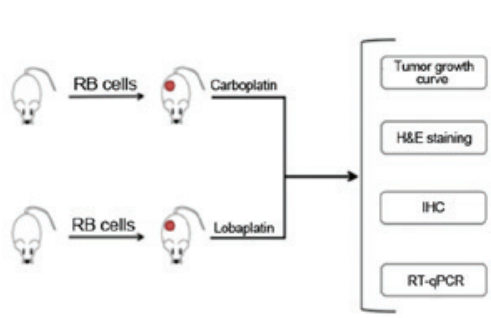

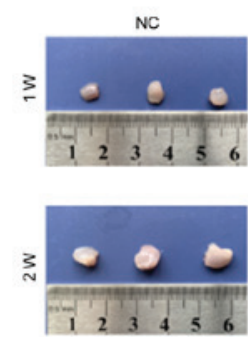

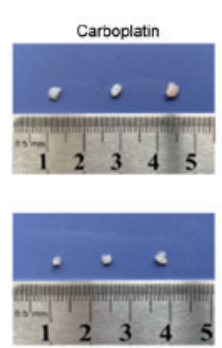

C

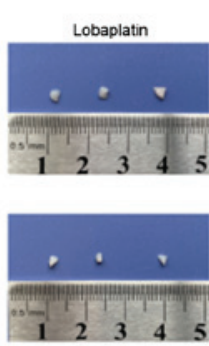

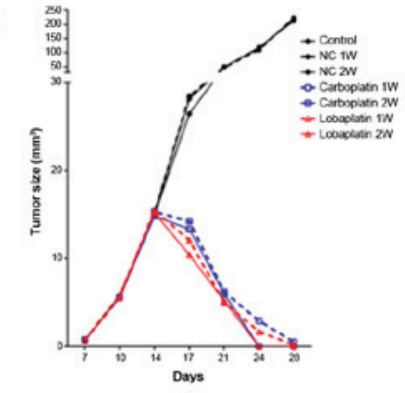

Df

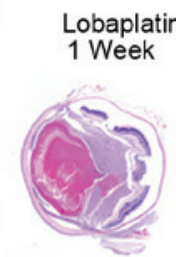

Dg Lobaplatin 2 Weeks
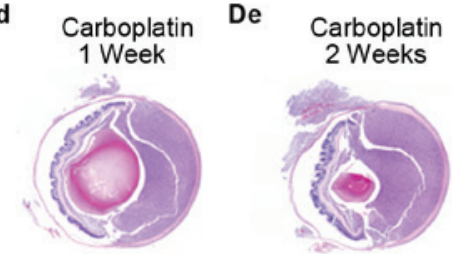

Ed

Eb

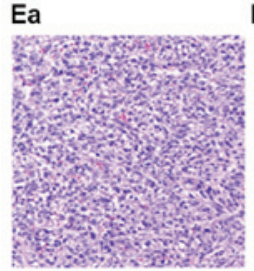

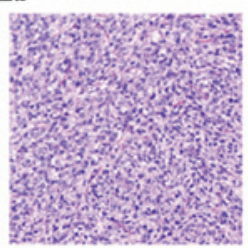

Ec

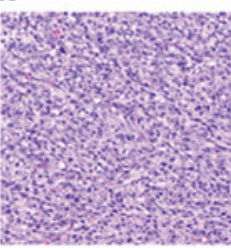

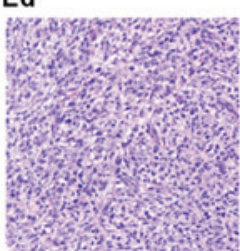

Ee

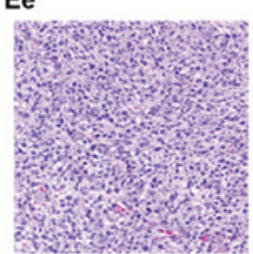

Ef

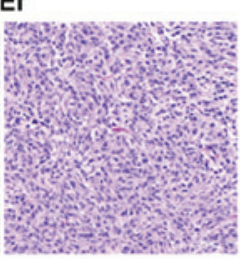

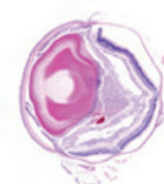

Eg

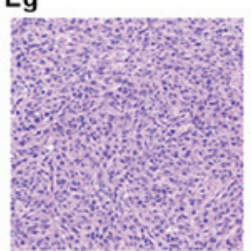

Figure 4. Carboplatin and lobaplatin at pharmacologic doses successfully inhibit the growth of human RB xenografts in vivo. (A) Animal experiments were divided into 4 analyses, including tumor growth curve generation, H\&E staining, immunohistochemistry, western blot analysis and RT-qPCR. (B and C) Tumor size in nude mice was monitored after the injection of carboplatin or lobaplatin from day 7 to day 28. H\&E staining of the (D-a-g) eyeball and (E-a-g) tumor tissue samples revealed that tumor growth was significantly inhibited after the drug injection, and the degree of inhibition mediated by lobaplatin was greater than that mediated by carboplatin (E-a-g). In (D and E) panels a-g represent the NC, control at 1 week, control at 2 weeks, carboplatin at 1 week, carboplatin at 2 weeks, lobaplatin at 1 week and lobaplatin at 2 weeks, respectively. Magnification, x1 for tumor size; x 20 for subcutaneous tissue H\&E staining and x2 for eyeball $\mathrm{H} \& \mathrm{E}$ staining. $\mathrm{H} \& \mathrm{E}$, hematoxylin and eosin.

carboplatin or lobaplatin treatment. In the 2nd week, the E2F1 mRNA expression level was $1.00 \pm 0.04$ in the $\mathrm{NC}$ group, evidently higher than the levels of $0.62 \pm 0.02(\mathrm{P}<0.001)$ and $0.54 \pm 0.01(\mathrm{P}<0.001)$ in the carboplatin and lobaplatin groups, respectively (Fig. 5A). Similarly, in the 2 nd week, the Cdc25a mRNA expression level was $3.10 \pm 0.04$ in the NC group, evidently higher than the levels of $1.66 \pm 0.05(\mathrm{P}<0.001)$ and $1.54 \pm 0.07(\mathrm{P}<0.001)$ in the carboplatin and lobaplatin groups, respectively (Fig. 5B). In the 2 nd week, the levels of Cdk2 mRNA expression were $1.00 \pm 0.03$ in the NC group, evidently higher than the levels of $0.82 \pm 0.05(\mathrm{P}<0.01)$ and $0.77 \pm 0.07$ $(\mathrm{P}<0.01)$ in the carboplatin and lobaplatin groups, respectively (Fig. 5C). IHC further revealed significant positive staining for E2F1 (Fig. 5D), Cdc25a (Fig. 5E) and Cdk2 (Fig. 5F) (depicted as brown dots) in ocular and subcutaneous tumors. However, substantially less positive staining was observed in both the carboplatin and lobaplatin groups compared with the control and $\mathrm{NC}$ groups in the 1 st and 2 nd weeks after treatment.

\section{Discussion}

$\mathrm{RB}$, a malignant intraocular tumor known to be most common among children (21), is often associated with distant metastasis and can be fatal if left untreated (22). Chemotherapy with drugs, such as carboplatin, etoposide and vincristine along with local consolidation treatment is the primary treatment strategy for RB. This strategy has improved patient survival rates to $\geq 95 \%$ higher (23). Recently, novel drugs have been developed for the treatment of RB. Platinum drugs are commonly used to treat malignancies; however, toxicity and resistance have limited their application in the clinical settings (24). Carboplatin is a conventional chemotherapeutic drug that has been used in the past few years for the treatment of RB; it has achieved good results in past research and clinical applications, but is accompanied by substantial side-effects $(25,26)$. The third-generation platinum derivative lobaplatin is a novel chemotherapeutic drug that has shown strong antitumor activity in different malignancies with fewer side-effects than carboplatin (10). However, to the best of our knowledge, no study to date has demonstrated the therapeutic effect of lobaplatin on RB. In the present study, it was confirmed that carboplatin and lobaplatin both exert antitumor effects on RB by inhibiting the E2F1 signaling pathway and that lobaplatin has lower cytotoxicity and a higher efficacy than carboplatin. The antitumor activity of lobaplatin results from the formation of DNA-drug adducts, mainly as GG and AG intra-strand cross-links. Lobaplatin influences the expression of the c-myc gene, which is involved in oncogenesis, apoptosis and cell proliferation. Carboplatin activity is very similar to lobaplatin, as it binds with DNA and affects replication; however, it can cause severe complications. In the course of clinical treatment, it is always accompanied by certain side-effects, such as autotoxicity, bone marrow suppression, nephrotoxicity and alopecia. To further explore more effective therapy for RB, the present study investigated the third-generation platinum derivative lobaplatin, a novel chemotherapeutic drug, that has 
A
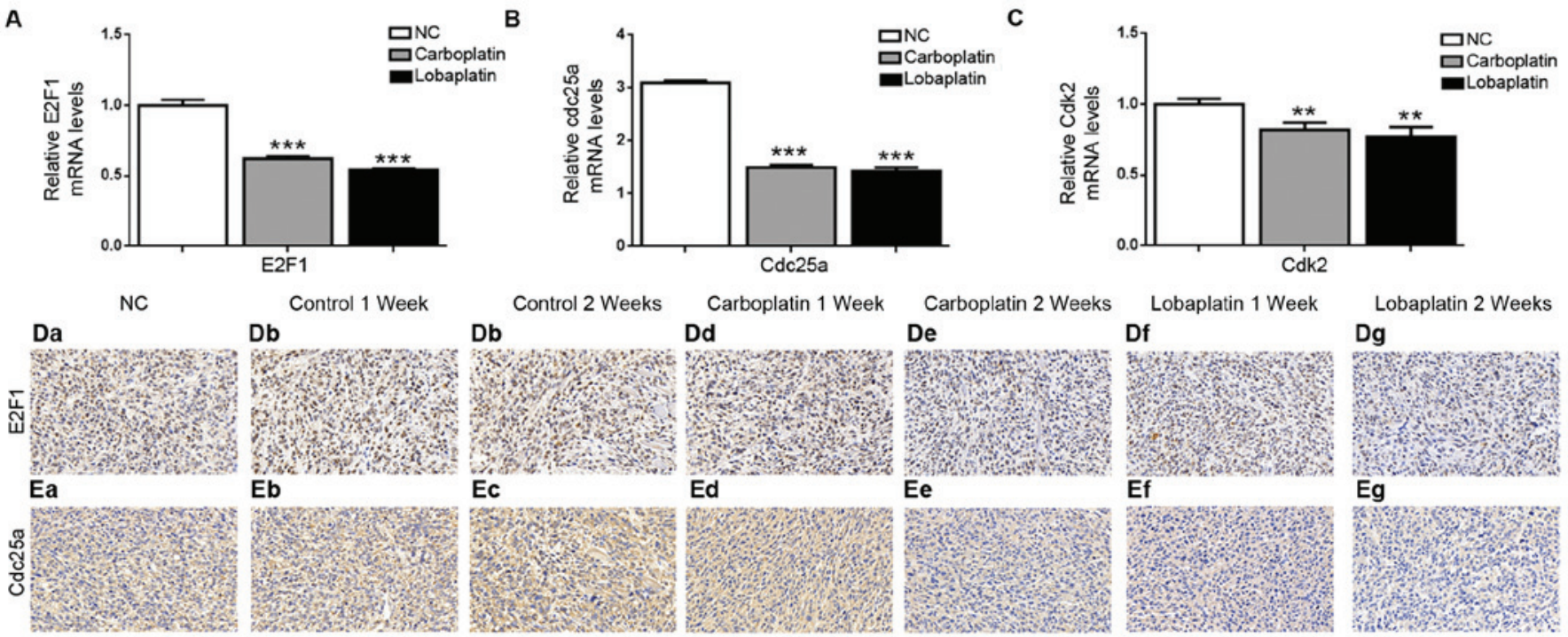

Lobaplatin 2 Weeks

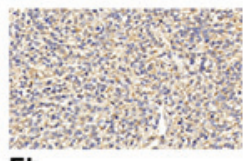

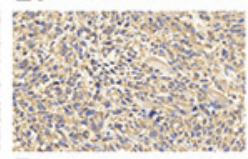

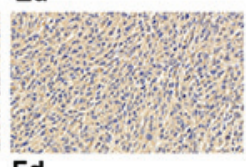

Ee

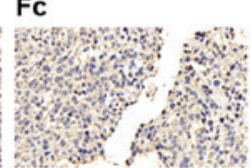

Fd

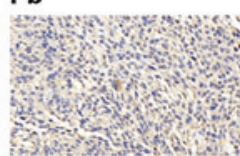

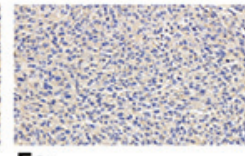

$\mathrm{Fe}$

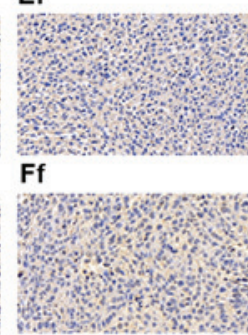

Dg

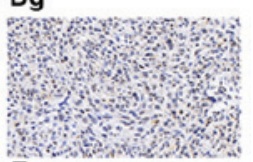

Eg

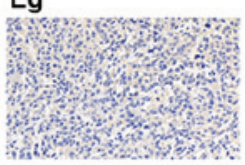

$\mathrm{Fg}$

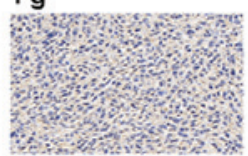

Figure 5. E2F1, Cdc25a and Cdk2 expression is decreased following carboplatin or lobaplatin treatment in vivo. RT-qPCR was employed to determine the mRNA levels of (A) E2F1, (B) Cdc25a and (C) Cdk2 in the NC, carboplatin and lobaplatin groups two weeks after the mice were treated. Immunohistochemical staining of tumor tissue samples revealed marked decreases in (D-a-g) E2F1-, (E-a-g) Cdc25a- and (F-a-g) Cdk2-positive cell frequencies; panels a-g represent the NC, control at 1 week, control at 2 weeks, carboplatin at 1 week, carboplatin at 2 weeks, lobaplatin at 1 week and lobaplatin at 2 weeks, respectively. Magnification, $x 20$. NS, not significant $(\mathrm{P}>0.05) ;{ }^{* *} \mathrm{P}<0.01$ and ${ }^{* * *} \mathrm{P}<0.001$ vs. NC group.

exhibited potent antitumor activity with fewer side-effects than carboplatin in non-small-cell lung and metastatic breast cancer $(27,28)$. In addition, the present study compared the therapeutic effects with a two-sided inequality test and concluded that lobaplatin exhibited lower cytotoxicity and exerted more prominent therapeutic effects than carboplatin on $\mathrm{RB}$ cells in vitro and in mice in vivo.

Several preclinical studies have established the antitumor activity of lobaplatin and have investigated the underlying mechanisms in multiple malignancies $(11,29-31)$; for example, lobaplatin has been found to induce caspase-dependent apoptosis and to increase the $\mathrm{Bax} / \mathrm{Bcl}-2$ ratio in esophageal squamous cell carcinoma (29). Lobaplatin may prevent cell cycle progression; similarly, it may play significant roles in stimulating apoptosis, altering the proteome and impeding invasion and migration. In addition, lobaplatin can reduce E2F1, cyclin D1, matrix metalloproteinase (MMP)-2, MMP-9, CDK4, CDK6 and Bcl-2 expression and/or upregulate p53, Bax, poly(ADP-ribose) polymerase (PARP), caspase- 3 , caspase- 8 and caspase- 9 expression. The present study revealed that in the Y79 RB cells, both carboplatin and lobaplatin function as potent antitumor agents. The cytotoxic effects of carboplatin and lobaplatin against Y79 RB cells were determined using cell viability assays. The results revealed that carboplatin and lobaplatin diminished Y79 cell proliferation in a dose- and time-dependent manner and caused the cells to swell significantly. The colony formation of the Y79 cells was also significantly reduced by carboplatin and lobaplatin. Over time, low-dose lobaplatin $(\leq 10 \mu \mathrm{g} / \mathrm{ml})$ inhibited tumor cell growth to a greater degree than low-dose carboplatin, although high-dose carboplatin $(\geq 60 \mu \mathrm{g} / \mathrm{ml})$ inhibited tumor cell growth to a greater degree than high-dose lobaplatin.
Tumorigenesis is associated with malfunctions in apoptosis, the induction of which is a vital mechanism of antitumor agents (32). Apoptosis induction and apoptosis levels are commonly determined to assess antitumor drugs. It has been found that lobaplatin causes substantial apoptosis in a number of cancer cell lines at various concentrations (32). In the present study, the apoptotic percentage of the Y79 RB cells was found to increase several-fold following treatment with carboplatin or lobaplatin in a dose-dependent manner. The total cell apoptotic percentage for carboplatin was higher than that for lobaplatin, although lobaplatin induced significantly higher rates of early apoptosis than carboplatin, with no significant difference in the late apoptotic percentage. The analysis of the effects of carboplatin and lobaplatin on the cell cycle in cultured cells revealed that the cells were arrested in either the G1 phase or $\mathrm{S}$ phase, and/or that the increases in the proportions of cells in the sub-G0/G1 populations were cell type-dependent. Similarly, cell cycle analysis revealed that carboplatin and lobaplatin treatment substantially increased the proportions of Y79 cells in the G0/G1 phase, while it reduced the proportions in the $\mathrm{S}$ phase. The results of the present study regarding cell cycle distribution are fairly consistent with those of another study which used lobaplatin for the treatment of non-small cell lung cancer (33).

A number of signaling pathways that play roles in tumor progression have been described, and a number of different cytokines can promote or inhibit tumorigenesis (34-36). Through gene screening and signaling pathway analyses, it was found that carboplatin and lobaplatin both suppressed tumor cell proliferation by inhibiting the E2F1/Cdc25a/Cdk2 pathway, particularly E2F1, which plays a significant and 
unique role in promoting the proliferation of tumor cells. Cell cycle progression is mediated by 2 regulators: $\mathrm{E} 2 \mathrm{~F} 1$ and $\mathrm{pRB}$. These regulators determine the progression of cells through the G1/S and G2/M checkpoints, which indicate whether a cell can proceed with DNA replication and cell division, respectively. The phosphorylation of $\mathrm{pRB}$ at specific amino acid residues by cyclin-dependent kinases (CDKs) inhibits heterodimerization with E2F1, while allowing E2F1 to be transcriptionally active. On the other hand, the dephosphorylation of $\mathrm{pRB}$ encourages heterodimerization with $\mathrm{E} 2 \mathrm{~F} 1$, while hindering E2F1 activity (37). E2F1 is an important transcription factor for a number of key proteins that can move cells through the G1/S transition and the $\mathrm{S}$ phase; thus, the progression of the cell cycle may be stalled if the activity of E2F1 activity is hindered. Out-of-control cell growth may be triggered by the overexpression of E2F1, which leads to tumorigenesis and cancer (38). By contrast, tumor growth, DNA repair issues and other anomalies may result from the blockade of E2F1 expression via the inhibition of apoptosis $(39,40)$. Neoplastic cell growth may also result from the E2F1-mediated activation of a transactivator of DNA synthesis genes. In the present study, the expression levels of E2F1 were significantly lower in both the carboplatin and lobaplatin groups than in the control group. The levels of $\mathrm{Cdc} 25 \mathrm{a}$ and $\mathrm{Cdk} 2$, which can promote tumor proliferation, were also significantly decreased following treatment with carboplatin or lobaplatin; thus, it was deduced that the E2F1/Cdc25a/Cdk2 pathway may be relevant to the therapeutic effects of carboplatin and lobaplatin on RB.

In the present study, in in vivo experiments, both carboplatin and lobaplatin were found to exert beneficial effects against tumor formation; the nude mice in the control group exhibited very rapid tumor growth, while those in the carboplatin and lobaplatin groups were sensitive to treatment. At the same time, it was found that the inhibitory effects of lobaplatin on tumors were more potent than those of carboplatin at both 1 and 2 weeks following treatment. The degree of tumor regression following lobaplatin treatment was significantly higher than that following carboplatin treatment. This finding indicates that both carboplatin and lobaplatin inhibit tumor growth and that the therapeutic effects of lobaplatin were more prominent than those of carboplatin. In previous studies, lobaplatin has been shown to be effective in inhibiting esophageal squamous cell carcinoma and colorectal cancer tumors $(11,31)$. Thus, it can be concluded that lobaplatin exerts similar inhibitory effects on RB.

H\&E staining of the eyeball and tumor tissue samples revealed that tumor growth was significantly inhibited following treatment and that lobaplatin caused a greater degree of inhibition than carboplatin. These results suggest that these drugs inhibit tumor growth. According to the immunohistochemical analysis of the tumor tissue, the expression levels of E2F1, $\mathrm{Cdc} 25 \mathrm{a}$ and $\mathrm{Cdk} 2$ in the tumors were significantly reduced following the injection of carboplatin or lobaplatin, and the reductions were in direct proportion to the degrees of tumor inhibition. In a previous study, arsenic was found to inhibit the phosphorylation of $\mathrm{pRB}$ at particular sites due to inhibition of the actions of E2F1 and CyclinE2/CDK2, contributing to decreases in the transcription of CCNE2 and the phosphatase activity of CDC25a and thus preventing dephosphorylation of CDK2 (35). Therefore, it can be speculated that these drugs negatively regulate tumors through the $\mathrm{E} 2 \mathrm{~F} 1 / \mathrm{Cdc} 25 \mathrm{a} / \mathrm{Cdk} 2$ signaling pathway.

In conclusion, the present study demonstrates that lobaplatin significantly inhibited the growth of RB with lower cytotoxicity and a higher efficiency than carboplatin, suppressing Y79 tumor cell proliferation by inhibiting the E2F1/Cdc25a/Cdk2 signaling pathway. However, a limitation of the present study has to be stated in that only 1 stem cell line was used in the in vitro experiments and thus further studies using other cell lines are required to verify the therapeutic effects of lobaplatin is meaningful clinically. On the whole, it can be concluded that lobaplatin may prove to be an efficient and high-performing drug for the treatment of RB and that further clinical evaluations should be conducted.

\section{Acknowledgements}

Not applicable.

\section{Funding}

The present study supported by the Natural Science Foundation of Guangdong Province (grant no. 2015A03033878).

\section{Availability of data and materials}

All data generated or analyzed during this study are included in this published article or are available at https://pan.baidu. com/s/1VDY1qaM_niaYpCEE7up4eA with the password 'oyah'.

\section{Authors' contributions}

$\mathrm{ZZ}$ and $\mathrm{JZ}$ conceived and designed the experiments. ZZ and JX performed the experiments. ZZ, HJ and JX analyzed the data. $\mathrm{ZZ}$ and $\mathrm{HJ}$ wrote the manuscript. ZZ, HJ, JX and JZ modified the manuscript. All authors read and approved the final manuscript.

\section{Ethics approval and consent to participate}

All animal experiments complied with the guidelines established by the Association for Research in Vision and Ophthalmology for the use of animals in ophthalmic and vision research and were approved by the Institutional Ethics Board of Guangzhou Women and Children's Medical Center.

\section{Patient consent for publication}

Not applicable.

\section{Competing interests}

The authors declare that they have no competing interests.

\section{References}

1. Hayden B, Jockovich ME, Murray TG, Kralinger MT, Voigt M, Hernandez E, Feuer W and Parel JM: Iontophoretic delivery of carboplatin in a murine model of retinoblastoma. Invest Ophthalmol Vis Sci 47: 3717-3721, 2006.

2. Castillo BV Jr and Kaufman L: Pediatric tumors of the eye and orbit. Pediatr Clin North Am 50: 149-172, 2003. 
3. Wiman KG: The retinoblastoma gene: Role in cell cycle control and cell differentiation. FASEB J 7: 841-845, 1993

4. MacCarthy A, Birch JM, Draper GJ, Hungerford JL, Kingston JE, Kroll ME, Onadim Z, Stiller CA, Vincent TJ and Murphy MF: Retinoblastoma in Great Britain 1963-2002. Br J Ophthalmol 93: 33-37, 2009.

5. Shields CL, Mashayekhi A, Au AK, Czyz C, Leahey A, Meadows AT and Shields JA: The International Classification of Retinoblastoma predicts chemoreduction success. Ophthalmology 113: 2276-2280, 2006.

6. Abramson DH, Lawrence SD, Beaverson KL, Lee TC, Rollins IS and Dunkel IJ: Systemic carboplatin for retinoblastoma: Change in tumour size over time. Br J Ophthalmol 89: 1616-1619, 2005.

7. Yanık Ö, Gündüz K, Yavuz K, Taçyıldız N and Ünal E: Chemotherapy in retinoblastoma: Current approaches. Turk J Ophthalmol 45: 259-267, 2015.

8. Smith SJ, Smith BD and Mohney BG: Ocular side effects following intravitreal injection therapy for retinoblastoma: A systematic review. Br J Ophthalmol 98: 292-297, 2014.

9. Winter U, Buitrago E, Mena HA, Del Sole MJ, Laurent V, Negrotto S, Francis J, Arana E, Sgroi M, Croxatto JO, et al: Pharmacokinetics, safety, and efficacy of intravitreal digoxin in preclinical models for retinoblastoma. Invest Ophthalmol Vis Sci 56: 4382-4393, 2015.

10. McKeage MJ: Lobaplatin: A new antitumour platinum drug Expert Opin Investig Drugs 10: 119-128, 2001

11. Shan L, Bai B, Lv Y, Xie B, Huang X and Zhu H: Lobaplatin suppresses proliferation and peritoneal metastasis of colorectal cancer in a preclinical model. Biomed Pharmacother 108: 486-491, 2018.

12. Yin CY, Lin XL, Tian L, Ye M, Yang XY and Xiao XY: Lobaplatin inhibits growth of gastric cancer cells by inducing apoptosis. World J Gastroenterol 20: 17426-17433, 2014.

13. Xie CY, Xu YP, Jin W and Lou LG: Antitumor activity of lobaplatin alone or in combination with antitubulin agents in non-small-cell lung cancer. Anticancer Drugs 23: 698-705, 2012.

14. Chen L, Cao H, Yu C and Feng Y: Lobaplatin inhibits prostate cancer progression in part by impairing AR and ERG signal. Fundam Clin Pharmacol 32: 548-557, 2018.

15. Wheate NJ, Walker S, Craig GE and Oun R: The status of platinum anticancer drugs in the clinic and in clinical trials. Dalton Trans 39: 8113-8127, 2010

16. Zhang Q, Cheng Y, Huang L, Bai Y, Liang J and Li X: Inhibitory effect of carboplatin in combination with bevacizumab on human retinoblastoma in an in vitro and in vivo model. Oncol Lett 14: 5326-5332, 2017

17. Gombos DS, Hungerford J, Abramson DH, Kingston J, Chantada G, Dunkel IJ, Antoneli CB, Greenwald M, Haik BG, Leal CA, et al: Secondary acute myelogenous leukemia in patients with retinoblastoma: Is chemotherapy a factor? Ophthalmology 114: 1378-1383, 2007.

18. Livak KJ and Schmittgen TD: Analysis of relative gene expression data using real-time quantitative PCR and the 2(-Delta Delta C(T)) Method. Methods 25: 402-408, 2001.

19. Moisan F, Francisco EB, Brozovic A, Duran GE, Wang YC, Chaturvedi S, Seetharam S, Snyder LA, Doshi P and Sikic BI: Enhancement of paclitaxel and carboplatin therapies by CCL2 blockade in ovarian cancers. Mol Oncol 8: 1231-1239, 2014

20. Liang H, Liu HZ, Wang HB, Zhong JY, Yang CX and Zhang B Dexmedetomidine protects against cisplatin induced acute kidney injury in mice through regulating apoptosis and inflammation. Inflamm Res 66: 399-411, 2017.

21. Tamboli A, Podgor MJ and Horm JW: The incidence of retinoblastoma in the United States: 1974 through 1985. Arch Ophthalmol 108: 128-132, 1990.

22. Kim DY, Choi JA, Koh JY and Yoon YH: Efficacy and safety of aflibercept in in vitro and in vivo models of retinoblastoma. J Exp Clin Cancer Res 35: 171, 2016.
23. Balmer A, Zografos L and Munier F: Diagnosis and current management of retinoblastoma. Oncogene 25: 5341-5349, 2006.

24. Dilruba S and Kalayda GV: Platinum-based drugs: Past, present and future. Cancer Chemother Pharmacol 77: 1103-1124, 2016.

25. Buckingham R, Fitt J and Sitzia J: Patients' experiences of chemotherapy: Side-effects of carboplatin in the treatment of carcinoma of the ovary. Eur J Cancer Care (Engl) 6: 59-71, 1997.

26. Kooijmans EC, Bökenkamp A, Tjahjadi NS, Tettero JM, van Dulmen-den Broeder E, van der Pal HJ and Veening MA: Early and late adverse renal effects after potentially nephrotoxic treatment for childhood cancer. Cochrane Database Syst Rev 3: CD008944, 2019.

27. Zhang H, Chen R, Wang X, Zhang H, Zhu X and Chen J: Lobaplatin-induced apoptosis requires p53-mediated p38MAPK activation through ROS generation in non-small-cell lung cancer. Front Oncol 9: 538, 2019.

28. Wu Y, Xu XY, Yan F, Sun WL, Zhang Y, Liu DL and Shen B: Retrospective study of the efficacy and toxicity of lobaplatin in combined chemotherapy for metastatic breast cancer. OncoTargets Ther 12: 4849-4857, 2019.

29. Du L, Fei Z, Song S and Wei N: Antitumor activity of lobaplatin against esophageal squamous cell carcinoma through caspase dependent apoptosis and increasing the $\mathrm{Bax} / \mathrm{Bcl} 2$ ratio. Biomed Pharmacother 95: 447 452, 2017.

30. Hua S, Kong X, Chen B, Zhuang W, Sun Q, Yang W, Liu W and Zhang Y: Anticancer mechanism of lobaplatin as monotherapy and in combination with paclitaxel in human gastric cancer. Curr Mol Pharmacol 11: 316-325, 2018.

31. Pan S, Sun Y, Sui D, Yang T, Fu S, Wang J, Hui B, Xi R, He C and Zhang X: Lobaplatin promotes radiosensitivity, induces apoptosis, attenuates cancer stemness and inhibits proliferation through PI3K/AKT pathway in esophageal squamous cell carcinoma. Biomed Pharmacother 102: 567-574, 2018.

32. Sun X, Lou LG, Sui DH and Wu XH: Preclinical activity of lobaplatin as a single agent and in combination with taxanes for ovarian carcinoma cells. Asian Pac J Cancer Prev 15: 9939-9943, 2014.

33. Zhang CY, Bao W and Wang LH: Downregulation of p16(ink4a) inhibits cell proliferation and induces G1 cell cycle arrest in cervical cancer cells. Int J Mol Med 33: 1577-1585, 2014.

34. Korah J, Canaff L and Lebrun JJ: The retinoblastoma tumor suppressor protein $(\mathrm{pRb}) / \mathrm{E} 2$ promoter binding factor 1 (E2F1) pathway as a novel mediator of TGFbeta induced autophagy. J Biol Chem 291: 2043-2054, 2016.

35. Sheldon LA: Inhibition of E2F1 activity and cell cycle progression by arsenic via retinoblastoma protein. Cell Cycle 16: 2058-2072, 2017.

36. Yang Y and Peng XW: The silencing of long non-coding RNA ANRIL suppresses invasion, and promotes apoptosis of retinoblastoma cells through the ATM-E2F1 signaling pathway. Biosci Rep 38: BSR20180558, 2018

37. Dyson N: The regulation of E2F by pRB-family proteins. Genes Dev 12: 2245-2262, 1998

38. Kent LN, Bae S, Tsai SY, Tang X, Srivastava A, Koivisto C, Martin CK, Ridolfi E, Miller GC, Zorko SM, et al: Dosage-dependent copy number gains in E2f1 and E2f3 drive hepatocellular carcinoma. J Clin Invest 127: 830-842, 2017.

39. Müller H, Bracken AP, Vernell R, Moroni MC, Christians F, Grassilli E, Prosperini E, Vigo E, Oliner JD and Helin K: E2Fs regulate the expression of genes involved in differentiation, development, proliferation, and apoptosis. Genes Dev 15: 267-285, 2001.

40. Poppy Roworth A, Ghari F and La Thangue NB: To live or let die - complexity within the E2F1 pathway. Mol Cell Oncol 2: e970480, 2015.

This work is licensed under a Creative Commons Attribution-NonCommercial-NoDerivatives 4.0 International (CC BY-NC-ND 4.0) License. 